\title{
Long-term Outcomes of a Dose-reduction Trial to Decrease Late Gastrointestinal Toxicity in Patients with Prostate Cancer Receiving Soft Tissue-matched Image-guided Intensity-modulated Radiotherapy
}

\author{
NAOMI SASAKI ${ }^{1}$, HIDEYA YAMAZAKI $^{1}$, DAISUKE SHIMIZU $^{1}$, GEN SUZUKI $^{1}$, KOJI MASUI $^{1}$, \\ SATOAKI NAKAMURA ${ }^{1}$, HARUUMI OKABE ${ }^{2}$, TATSUYUKI NISHIKAWA ${ }^{2}$ and KEN YOSHIDA ${ }^{3}$ \\ ${ }^{1}$ Department of Radiology, Graduate School of Medical Science, \\ Kyoto Prefectural University of Medicine, Kyoto, Japan; \\ ${ }^{2}$ Department of Radiology, Ujitakeda Hospital, Uji, Japan; \\ ${ }^{3}$ Department of Radiology, Osaka Medical College, Takatsuki, Japan
}

\begin{abstract}
Background/Aim: We experienced an unexpected high incidence of gastrointestinal (GI) toxicity in patients undergoing image-guided intensity-modulated radiotherapy (IG-IMRT) using helical tomotherapy in our initial 2.2 Gy/fraction schedule for prostate cancer; hence, a dosereduction trial from 2.2 Gy to 2 Gy/fraction was conducted using modified planning target volume (PTV) contouring. Patients and Methods: We compared 130 patients treated using 2.2 Gy/fraction (Group A) and 144 treated using the 2 Gylfraction (Group B) with modified PTV (excluding rectal volume) with a median follow-up period of 62 months. Prescribed dose was 72.6-74.8 Gy in 33-34 fractions (Group A) and 72-74 Gy in 36-37 fractions (Group B). Results: Patients in Group B had a reduced rectal and bladder V10V70 and were irradiated at the maximal dose. Their cumulative incidence of grade $\leq 2$ GI toxicity at 5 years improved from $10.1 \%$ [95\% confidence interval (CI), 4.9$15.3 \%$ ] to $1.4 \%$ (0-3.3\%). Grade $2 \leq$ urinary toxicity also decreased from $5.5 \%(1.5-9.4 \%)$ in Group A to $1.4 \%$ $(0-3.3 \%, p=0.0167)$ in Group B. The biochemical failure-free 5 -year survival rate was $89.1 \%(95 \% C I=83.6-95.4 \%)$ and $87.5 \%$ (82.0-92.9\%, $p=0.75)$ in groups $A$ and $B$, respectively. Conclusion: The reduced dose fraction schedule decreased the incidence of late GI toxicity without compromising
\end{abstract}

Correspondence to: Dr. Hideya Yamazaki, Department of Radiology, Kyoto Prefectural University of Medicine, 465 Kajiicho Kawaramachi Hirokoji, Kamigyo-ku, Kyoto 602-8566 Japan. Tel: +81 752515618, Fax: +81 752515840, e-mail: hideya10@hotmail.com

Key Words: Prostate cancer IGRT, IMRT, rectal bleeding, gastrointestinal toxicity, helical tomotherapy. prostate-specific antigen control. Careful target volume definition and fraction size are important even for IG-IMRT.

To achieve good outcomes for prostate cancer with little adverse events, intensity-modulated radiotherapy (IMRT) has a merit $(1,2)$ to reduce adverse events than threedimensional conformal radiotherapy (3D-CRT) (3-5). In addition, image-guided (IG) RT contains meticulous technique for more precise dose delivery, which may result in a higher control rate with reduced toxicity (6-8). Because helical tomotherapy (HT) permits the delivery of IG-IMRT using megavoltage computed tomography (MVCT), we began hypofractionated IG-IMRT (Group A) using soft tissue matching for prostate cancer in 2006. However, a paradoxically higher incidence of late GI toxicity was observed even with IG-IMRT than that observed in other studies (9). This prompted us to modify our dose fraction schedule and PTV contouring (Group B), and we thereafter began a modified schedule. Here, we report on a comparison of the results of the initial $2.2 \mathrm{~Gy} /$ fraction schedule (Group A) and the modified $2 \mathrm{~Gy} /$ fraction schedule (Group B) to reduce late GI toxicity with IG-IMRT after a long term follow-up of $>5$ years.

\section{Patients and Methods}

Patients. A total of 274 patients with stage T1-T4 N0M0 prostate cancer who were treated using IG-IMRT from June 2007 to September 2011 were included in this study. We employed 2.2 Gy fraction schedule between June 2007 to June 2009 in 130 patients (Group A) and a modified 2 Gy fraction schedule from June 2009 to September 2011 in 144 patients (Group B). All patients had histology-proven adenocarcinoma. Patients were staged according to the 2002 International Union Against Cancer version 6 staging 
classification system. The median patient age was 71 (range=51-86 years) years. Patients' clinical characteristics are shown in Table I. Prostate specific antigen (PSA) failure was defined using the Phoenix definition (nadir, $+2 \mathrm{ng} / \mathrm{ml}$ ) or as the start of salvage hormonal therapy. Common Terminology Criteria for Adverse Events version 3.0 Toxicity was applied to toxicity analysis. All patients provided informed written consent. This study was conducted in accordance with the Declaration of Helsinki.

Treatment planning. Detailed method was prescribed in previous manuscript (9). In brief, approximately 1 week before treatment initiation, we obtained CT and magnetic resonance imaging (MRI) data for treatment planning. At this time, each patient followed instructions for rectal emptying and bladder filling to minimize the interfraction motion. Patients were placed in the supine position, and CT was performed with 2-mm slice thickness. MRI (T1w and $\mathrm{T} 2 \mathrm{w}$ ) and CT images were fused to make meticulous radiotherapy planning. The clinical target volume (CTV) was defined for the prostate and proximal seminal vesicles and prostate only in the low risk group (Damico's: classification: stage, T1c; Gleason score, $<7$; and PSA, $<10 \mathrm{ng} / \mathrm{ml}$ ). In the initial $2.2 \mathrm{~Gy} /$ fraction schedule, the CTV-PTV expansion margin was $5 \mathrm{~mm}$ in all directions, not avoiding the rectum. Pelvic nodal irradiation was not used. Ninetyfive percent of PTV (D95) received at least the prescribed dose of $74.8 \mathrm{~Gy}$ in 34 fractions ( $2.2 \mathrm{~Gy} /$ fraction, Group A), unless the tumor was low risk in which case a dose of $72.6 \mathrm{~Gy}$ in 33 fractions was used. After the schedule was modified, the prescribed dose was reduced to 74 Gy (D95) in 37 fractions for the high and intermediate risk groups and $72 \mathrm{~Gy}$ in 36 fractions for the low risk group ( 2 Gy/fraction, Group B). The posterior CTV-PTV expansion margin was also reduced to $3 \mathrm{~mm}$ and the rectal contour was omitted from PTV, except in cases where the tumor was located adjacent to the rectum.

We defined the bladder and rectum as solid organs at risk. Rectal volumes were contoured on axial slices from the recto-sigmoid junction to the anal verge. Planning constraints were set for the rectum and bladder: $35 \%$ and $18 \%$ of the rectal volume received $<40 \mathrm{~Gy}$ and $<60 \mathrm{~Gy}$, respectively, and $50 \%$ and $25 \%$ of the bladder volume received $<40 \mathrm{~Gy}$ and $<65 \mathrm{~Gy}$, respectively.

Daily treatment. All patients were treated using HT. MVCT scan was performed before each treatment to confirm the location of PTV and to verify that rectum and bladder conditions were met (9). We then corrected the registered position to a simulated CT using soft tissue matching. We defined an action level of rectal displacement if the most anterior rectal region moved $>5 \mathrm{~mm}$ and could not be corrected using a couch adjustment (10). In these cases, the patient was asked to get up from the couch and void the rectum. If necessary, a rectal enema was used to dislodge a large rectal stool and/or rectal gas (10). The accuracy and reproducibility of these methods have been reported in a previous study (11). Late GI toxicity was defined as any toxicity experienced 3 months after the completion of radiotherapy. We then determined whether 10-70 Gy volumes received in the rectum and bladder, planning target volume, age, risk classification, use of hormonal therapy, and treatment schedules correlated with adverse events.

Statistical analysis. StatView 5.0 statistical software was used for statistical analyses. Percentages were analyzed using the chi-square test, and Student's $t$-test was used for normally distributed data. The
Mann-Whitney $U$-test for skewed data was used to compare means or medians, and the Kaplan-Meier method was used to analyze PSA control, overall survival, and cumulative risk of toxicities. Cox's proportional hazard model (survival and toxicity) were used for uniand multivariate analyses (variables with $p<0.3$ in the univariate analysis and those that were not strongly correlated were included in the multivariate analysis; i.e., $\mathrm{V} 40, \mathrm{~V} 60$, and $\mathrm{V} 70$ ). A receiver operating characteristic analysis was performed to generate the area under curve (AUC) using $\mathrm{R}$ software for statistically significant DVH parameters (12). $p<0.05$ was considered as statistically significant.

\section{Results}

The median follow-up for the entire cohort was 62 (range=12-97 months) months. A comparison of the two schedule backgrounds is shown in Table I. Group A showed a higher Gleason score and shorter follow-up periods. Table II shows the incidence of late GI and urinary toxicities. Late GI toxicity grades 1, 2, and 3 occurred in 18 (14\%), 11 (8\%), and three $(2 \%)$ patients in Group $\mathrm{A}$ and in $12(8 \%)$, zero $(0 \%)$, and two (1\%) patients in Group B $(p=0.001)$, respectively. Grade 1, 2, and 3 late urinary toxicities occurred in $12(9 \%), 10(8 \%), 0(0 \%)$ patients in Group A and in $25(17 \%)$, one $(1 \%)$, and one $(1 \%)$ in Group B, respectively $(p=0.0058)$. There was a statistically significant reduction in late toxicities using the modified Group B schedule. The cumulative incidence of late GI and urinary toxicities is shown in Figure 1 . The incidence of $\geq$ grade 2 GI toxicity was $10.1 \%$ [95\% confidence interval (CI), 4.9$15.3 \%$ ] and $1.4 \%(95 \% \mathrm{CI}=0-3.3 \%, p=0.0014)$ for groups $\mathrm{A}$ and $\mathrm{B}$, respectively (Figure 1). The incidence of $\geq$ grade 2 urinary toxicity was $5.5 \%(95 \% \mathrm{CI}=1.5-9.4 \%)$ in Group A and $1.4 \%(95 \% \mathrm{CI}=0-3.3 \%, p=0.0167)$ in Group B (Figure 1). Therefore, the modified strategy significantly reduced late $\geq$ grade 2 GI and GU toxicities. Simultaneously, all GI and GU DVH parameters (V10-V70) decreased under the modified Group A schedule (Table III).

In addition, rectal V20-V70 showed a statistically significant correlation to $\geq$ grade 2 GI toxicity (Table IV), whereas no correlation was observed between bladder DVH parameters and urinary toxicity (data not shown). Among them, V60 showed the highest AUC 0.722 with a threshold of $10.0 \%$ (sensitivity, $81.2 \%$; specificity, $52.7 \%$ ). This parameter was then applied to a multivariate analysis as a representative DVH analysis. The multivariate analysis revealed that schedule was the only statistically significant factor for $\mathrm{GI} \mathrm{G} 2 \leq(\mathrm{HR}=8.795$; 95\%CI=1.110-64.649) (Table $\mathrm{V})$. The biochemical failure-free 5-year survival rate was $89.1 \%(95 \% \mathrm{CI}=83.6-95.4 \%)$ and $87.5 \% \quad(82.0-92.9 \%$, $p=0.75)$ in groups A and B, respectively; it was $84.1 \%(84 \%$ for Group A and $85 \%$ for Group B) for the high-risk group, 93\% (95\% and $89 \%$ ) for the intermediate group, and $96 \%$ (96\% and 96\%) for the low risk group $(p=0.021)$. The 
Table I. Characteristics and treatment factors of patients.

\begin{tabular}{|c|c|c|c|c|c|c|c|}
\hline \multirow[t]{2}{*}{ Variables } & \multirow[t]{2}{*}{ Strata } & \multicolumn{2}{|c|}{$\begin{array}{c}\text { Group A (2.2 Gy fraction) } \\
\qquad n=130\end{array}$} & \multicolumn{3}{|c|}{$\begin{array}{l}\text { Group B (2 Gy fraction) } \\
\qquad \mathrm{n}=144\end{array}$} & \multirow[t]{2}{*}{$p$-Value } \\
\hline & & No. or Median (range) & $(\%)$ & & No. or Median (range) & $(\%)$ & \\
\hline Age & & $71(51-83)$ & & & $72(54-86)$ & & 0.076 \\
\hline \multirow[t]{4}{*}{$\mathrm{T}$ category } & 1 & 41 & $(32 \%)$ & & 46 & $(32 \%)$ & 0.78 \\
\hline & 2 & 56 & $(43 \%)$ & & 63 & $(44 \%)$ & \\
\hline & 3 & 33 & $(25 \%)$ & & 34 & $(24 \%)$ & \\
\hline & 4 & 0 & $(0 \%)$ & & 1 & $(1 \%)$ & \\
\hline iPSA & $\mathrm{ng} / \mathrm{ml}$ & $10.5(4-265)$ & & & $9.3(4.5-290)$ & & 0.57 \\
\hline \multirow[t]{3}{*}{ Gleason score } & -6 & 51 & $(39 \%)$ & & 38 & $(26 \%)$ & 0.04 \\
\hline & 7 & 36 & $(28 \%)$ & & 42 & $(29 \%)$ & \\
\hline & $8-$ & 43 & $(33 \%)$ & & 66 & $(46 \%)$ & \\
\hline \multirow[t]{3}{*}{ Damico's risk classification } & Low & 23 & $(18 \%)$ & & 25 & $(17 \%)$ & 0.64 \\
\hline & Intermediate & 38 & $(29 \%)$ & & 35 & $(24 \%)$ & \\
\hline & High & 69 & $(53 \%)$ & & 84 & $(58 \%)$ & \\
\hline \multirow[t]{2}{*}{ Prescribed dose } & 74.8Gy & 107 & $(82 \%)$ & $74 \mathrm{~Gy}$ & 119 & $(83 \%)$ & NA \\
\hline & $72.6 \mathrm{~Gy}$ & 23 & $(18 \%)$ & $72 \mathrm{~Gy}$ & 25 & $(17 \%)$ & \\
\hline \multirow[t]{2}{*}{ Hormonal therapy } & Yes & 81 & $(62 \%)$ & & 99 & $(69 \%)$ & 0.26 \\
\hline & No & 49 & $(38 \%)$ & & 45 & $(31 \%)$ & \\
\hline Follow-up & Months & $81.5(23.2-97.2)$ & & & $68.8(36.8-85.8)$ & & 0.0001 \\
\hline
\end{tabular}

*Bold values indicate statistical significance, NA; not available.

Table II. Characteristics of late toxicities.

\begin{tabular}{|c|c|c|c|c|c|c|}
\hline \multirow[t]{2}{*}{ Variables } & \multirow[t]{2}{*}{ Strata } & \multicolumn{2}{|c|}{$\begin{array}{c}\text { Group A (2.2 Gy fraction) } \\
n=130\end{array}$} & \multicolumn{2}{|c|}{$\begin{array}{c}\text { Group B (2 Gy fraction) } \\
n=144\end{array}$} & \multirow[t]{2}{*}{$p$-Value } \\
\hline & & No. PT & $(\%)$ & No. PT & $(\%)$ & \\
\hline \multirow[t]{4}{*}{ Gastrointestinal toxicity } & 0 & 98 & $(75 \%)$ & 130 & $(90 \%)$ & 0.001 \\
\hline & 1 & 18 & $(14 \%)$ & 12 & $(8 \%)$ & \\
\hline & 2 & 11 & $(8 \%)$ & 0 & $(0 \%)$ & \\
\hline & 3 & 3 & $(2 \%)$ & 2 & $(1 \%)$ & \\
\hline \multirow[t]{4}{*}{ Genitourinary toxicity } & 0 & 108 & $(83 \%)$ & 117 & $(81 \%)$ & 0.0058 \\
\hline & 1 & 12 & $(9 \%)$ & 25 & $(17 \%)$ & \\
\hline & 2 & 10 & $(8 \%)$ & 1 & $(1 \%)$ & \\
\hline & 3 & 0 & $(0 \%)$ & 1 & $(1 \%)$ & \\
\hline
\end{tabular}

*Bold values indicate statistical significance.

overall 5-year survival rate was $100 \%$ and $99.3 \%$ $(95 \% \mathrm{CI}=97.9-100.7 \% ; p=0.668)$ in groups $\mathrm{A}$ and $\mathrm{B}$, respectively.

\section{Discussion}

IMRT is an established modality for reducing the incidence of GI adverse events. A pioneer group study reduced GI toxicity from $14 \%$ using $3 \mathrm{D}$-CRT to $2 \%$ using IMRT $(1,2$, 7). Furthermore, IGRT enabled us to deliver precise radiation exposure of the prostate, reducing uncertain exposure obtained using non-IGRT methods. Therefore, IG-IMRT has a potential to perform a higher-dose irradiation of the target lesion without unnecessary irradiation of normal tissues, and its use has increased in the recent years (6-8).

Although almost all IG-IMRT series reported up to $5 \%$ gastrointestinal toxicity $(1,6,8,13-15)$, we encountered $7-10 \%$ GI toxicity $\geq$ grade 2 in the initial Group A schedule (9), which prompted us to undertake this dose fraction deescalation trial. This unexpected high incidence of GI toxicity may have been caused by several factors. Although soft tissue matching enables us to deliver more accurate 

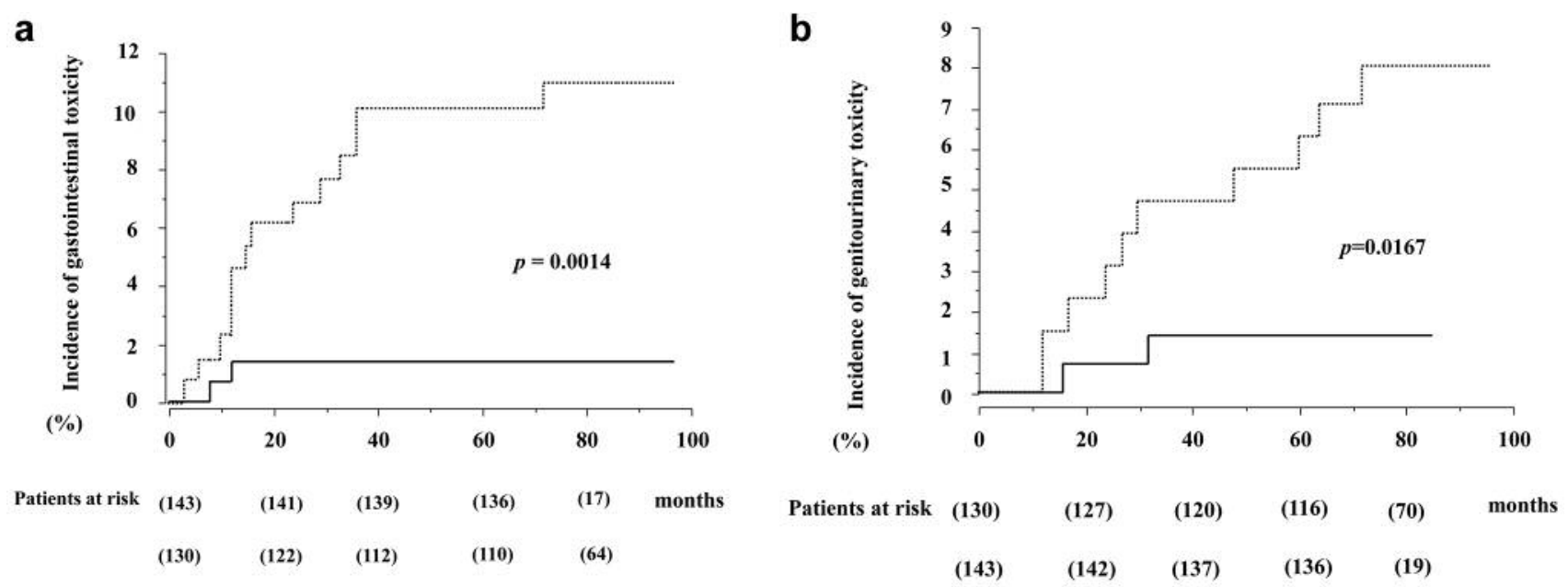

Figure 1. Cumulative incidence grade $2 \leq$ toxicity. Modified standard dose-fractionation (group B; 2 Gy/fraction) reduced late gastrointestinal and genitourinary toxicities than hypofractionation (group A; 2.2 Gy/fraction). a) Gastrointestinal toxicity. $b$ ) Genitourinary toxicity.

Table III. Comparison of treatment factors.

\begin{tabular}{|c|c|c|c|c|}
\hline Variables & & $\begin{array}{c}\text { Group A (2.2 Gy fraction) } \\
\mathrm{n}=130 \\
\text { Median (range) }\end{array}$ & $\begin{array}{c}\text { Group B (2 Gy fraction) } \\
\text { n=144 } \\
\text { No. or Median (range) }\end{array}$ & $p$-Value \\
\hline \multicolumn{5}{|l|}{ Target } \\
\hline PTV volume & $\mathrm{cm}^{3}$ & $94.1(40.8-265.9)$ & $84.3(45.7-217.6)$ & 0.14 \\
\hline \multicolumn{5}{|l|}{ Rectum } \\
\hline V10 & $\%$ & $82(40-98)$ & 74 (34-99) & $<0.0001$ \\
\hline V20 & $\%$ & $82(40-98)$ & $43(18-75)$ & $<0.0001$ \\
\hline V30 & $\%$ & $55(27-79)$ & $29(5-43)$ & $<0.0001$ \\
\hline $\mathrm{V} 40$ & $\%$ & $35(18-49)$ & $19(6-32)$ & $<0.0001$ \\
\hline V50 & $\%$ & $22(11-30)$ & $12(2-23)$ & $<0.0001$ \\
\hline V60 & $\%$ & $14(7-23)$ & $5(1-14)$ & $<0.0001$ \\
\hline V70 & $\%$ & $5(1-11)$ & $1(0-6)$ & $<0.0001$ \\
\hline Max dose & Gy & $78.5(73.6-81.3)$ & $75.8(26.8-79.2)$ & $<0.0001$ \\
\hline \multicolumn{5}{|l|}{ Bladder } \\
\hline V10 & $\%$ & $90.5(40-100)$ & $76(7-100)$ & $<0.0001$ \\
\hline V20 & $\%$ & 75 824-100) & $57.5(27-88)$ & $<0.0001$ \\
\hline V30 & $\%$ & $58(23-85)$ & $42(18-68)$ & $<0.0001$ \\
\hline V40 & $\%$ & $40(16-59)$ & $31.5(13-50)$ & $<0.0001$ \\
\hline V50 & $\%$ & $28(9-40)$ & $22(9-36)$ & $<0.0001$ \\
\hline V60 & $\%$ & $18(7-33)$ & $13(5-25)$ & $<0.0001$ \\
\hline V70 & $\%$ & $10(3-14)$ & $7(2-13)$ & $<0.0001$ \\
\hline Max dose & Gy & $78.9(74.8-81.1)$ & $78.2(74-142.1)$ & $<0.0001$ \\
\hline
\end{tabular}

*Bold values indicate statistical significance.

irradiation, anterior rectal wall may receive higher dose of irradiation compared with that obtained with conventional bone matching. Furthermore, hypo-fractionation may cause higher GI toxicity (17) because calculation of BED indicates that using $\alpha / \beta=3$ Gy for normal tissues, total doses of 72.6-
74.8 Gy for Group A equates to 2 Gy equivalent doses of 75.5-77.8 Gy.

Dose fractionation is an important factor for GI toxicity even using IG-IMRT. Lieng et al. (18) reported higher (21\%) grade $2 \leq$ GI toxicity for the $66 \mathrm{~Gy} / 22$ fraction 
Table IV. Predictive DVH parameters for late gastrointestinal toxicity grade 2 or more.

\begin{tabular}{|c|c|c|c|c|}
\hline Variables & & $\begin{array}{c}\text { Rectal Bleeding } \geq \mathrm{G} 2 \text { positive } \\
\mathrm{n}=16 \\
\text { Median (range) }\end{array}$ & $\begin{array}{c}\text { Rectal bleeding } \geq \mathrm{G} 2 \text { negative } \\
\mathrm{n}=258 \\
\text { Median (range) }\end{array}$ & $p$-Value \\
\hline \multicolumn{5}{|l|}{ Target } \\
\hline PTV volume & $\mathrm{cm}^{3}$ & $88.1(48.3-190.1)$ & $86.5(40.8-265.9)$ & 0.92 \\
\hline \multicolumn{5}{|l|}{ Rectum } \\
\hline V10 & $\%$ & $97(55-100)$ & $85(10-100)$ & 0.17 \\
\hline V20 & $\%$ & $78.5(40-96)$ & $54(18-98)$ & 0.02 \\
\hline V30 & $\%$ & $51.5(27-79)$ & $36(5-77)$ & 0.0094 \\
\hline V40 & $\%$ & $35(18-40)$ & $25(6-49)$ & 0.0036 \\
\hline V50 & $\%$ & $22.5(11-25)$ & $17(2-30)$ & 0.0126 \\
\hline V60 & $\%$ & $13.5(7-18)$ & $9(1-23)$ & 0.0029 \\
\hline V70 & $\%$ & $5(2-11)$ & $2(0-11)$ & 0.0032 \\
\hline Max dose & Gy & $77.9(73.8-79.5)$ & $76.9(26.8-81.3)$ & 0.11 \\
\hline
\end{tabular}

*Bold values indicate statistical significance.

Table V. Univariate and multi-variate analysis for late gastrointestinal toxicity grade 2 or more.

\begin{tabular}{|c|c|c|c|c|c|c|c|c|c|c|}
\hline \multirow[t]{2}{*}{ Variable } & \multirow[t]{2}{*}{ Strata } & \multirow[t]{2}{*}{$\mathrm{n}$} & \multirow[t]{2}{*}{ G2- } & \multirow[t]{2}{*}{$(\%)$} & \multicolumn{3}{|c|}{ Univariate analysis } & \multicolumn{3}{|c|}{ Multivariate analysis } \\
\hline & & & & & HR & $95 \% \mathrm{CI}$ & $p$-Value & HR & $95 \% \mathrm{CI}$ & $p$-Value \\
\hline \multirow[t]{2}{*}{ Age, years } & $<71$ & 157 & 7 & $(4 \%)$ & 0.573 & $0.213-1.539$ & 0.27 & 0.581 & $0.215-1.572$ & 0.2848 \\
\hline & $71 \leq$ & 117 & 9 & $(8 \%)$ & & & & & & \\
\hline \multirow[t]{2}{*}{ Damico's risk classification } & Low & 48 & 4 & $(8 \%)$ & 1.552 & $0.5-4.81$ & 0.4468 & & & \\
\hline & Intermediate-High & 226 & 12 & $(5 \%)$ & & & & & & \\
\hline \multirow[t]{2}{*}{ V40 } & $<26 \%$ & 136 & 4 & $(3 \%)$ & 0.343 & $0.110-1.065$ & 0.064 & & & \\
\hline & $26 \% \leq$ & 138 & 12 & $(9 \%)$ & & & & & & \\
\hline \multirow[t]{2}{*}{ V60 } & $<10 \%$ & 139 & 3 & $(2 \%)$ & 0.227 & $0.064-0.797$ & 0.0207 & 1.181 & $0.203-6.867$ & 0.853 \\
\hline & $10 \% \leq$ & 135 & 13 & $(10 \%)$ & & & & & & \\
\hline \multirow[t]{2}{*}{ V70 } & $<2.5 \%$ & 139 & 3 & $(2 \%)$ & 0.227 & $0.064-0.797$ & 0.0094 & & & \\
\hline & $2.5 \% \leq$ & 135 & 13 & $(10 \%)$ & & & & & & \\
\hline \multirow[t]{2}{*}{ Hormonal therapy } & Yes & 180 & 9 & $(5 \%)$ & 0.674 & $0.251-1.811$ & 0.434 & & & \\
\hline & No & 94 & 7 & $(7 \%)$ & & & & & & \\
\hline \multirow[t]{2}{*}{ Treatment schedule } & Group A (2.2 Gy fraction) & 116 & 14 & $(12 \%)$ & 7,74 & $1.756-34.128$ & 0.0069 & 8,795 & $1.110-64.649$ & 0.0395 \\
\hline & Group B (2 Gy fraction) & 142 & 2 & $(1 \%)$ & & & & & & \\
\hline
\end{tabular}

Bold values indicate statistical significance.

schedule compared to $4 \%$ in the $60 \mathrm{~Gy} / 20$ fraction schedule over 8 years (18). This was consistent with our data where reduced dose fractionation (from $2.2 \mathrm{~Gy}$ to $2 \mathrm{~Gy} /$ fraction) decreased late toxicities even using IG-IMRT. Our dosevolume analysis revealed a significant reduction in V10-V70 of both rectal and bladder volumes by the modified schedule, and this may have directly influenced the reduction of toxicities (13).

There are several authorized dose constraint parameters in the 3D-CRT era. For instance, quantitative analyses of normal tissue effects in the clinic provided a suggestion that if patients met the criteria of V $50<50 \%$, V60 $<35 \%$, $\mathrm{V} 65<25 \%$, V70 $<20 \%$, and V75 $<15 \%$, then grade $2 \mathrm{GI}$ toxicity could be $<15 \%$ using 3D-CRT (19). However, little information was provided for DVH parameter for IMRT and IG-IMRT. Pederson et al. reported that freedom from $\geq$ grade 2 gastrointestinal toxicity after a few years was $100 \%$ for males with a rectal V70 $\leq 10 \%$, V65 $\leq 20 \%$, and V40 $\leq 40 \%$ using IMRT (20). Almost all our patients fulfilled these criteria (Table IV); however, they experienced grade $2 \leq$ GI toxicity. Therefore, our DVH analysis contains some uncertainty and does not always 
warrant the safety of IG-IMRT. Several authors proposed custom-made constraints based on generic and patientspecific risk factors $(21,22)$. An Italian group attempted to examine the influence of a prior abdominal surgery and its correlation with G2-G3 bleeding $(21,22)$. They proposed a modified constraint for bleeding of V70 <15\% and V75 $<5 \%$ for patients with a history of abdominal or pelvic surgeries, which otherwise was V70 $<25 \%$ and V75 $<15 \%-20 \%$.

It is interesting that urinary toxicity was also reduced under the modified schedule. It may be partly because of reduced dose fractionation. In addition, IG-IMRT could add merit to decreased GI toxicity. Zelefsky found a reduction in GI toxicity from $20 \%$ to $10.4 \%$ in the IG-IMRT group presented in the non-IG-IMRT era (7). They commented that enhanced accuracy associated with IGRT resulted in less exposure of the bladder or bladder neck region to high doses of irradiation, translating into a reduced incidence of late toxicity.

In a previous study, the margin was reduced from 10 to 6 $\mathrm{mm}$ circumferentially around the prostate, including the prostate-rectal interface region by IG-IMRT using a fiducial marker (7). Then, we tried to assess the required margin at our institution using repeated MVCT before and after each treatment session throughout the radiotherapy periods (9-11) and reduced the posterior CTV-PTV expansion margin of the prostate from 5 to $3 \mathrm{~mm}$ in group B and simultaneously reduced the fraction dose from 2.2 to $2 \mathrm{~Gy}$. Wust et al. compared gold marker-based registrations and native MVCT and concluded that there was little difference between the two techniques (23).

There are several limitations to our analysis. First, as this trial was not a randomized control trial, further validation by means of external data is required. Second, we did not examine other factors (i.e., DM, drug usage, PS) that may influence GI toxicity because our aim was to compare between two radiotherapy schedules. Third, a patient quality of life (QOL) assessment would be useful and would provide further merit of dose de-escalation. Lastly, although we revealed safety of schedule B ( $74 \mathrm{~Gy} / 37$ fractions), it is now not a standard schedule especially for intermediate to high risk patients (24). We have, therefore, elevated the prescribed dose to $78 \mathrm{~Gy} / 39$ fractions after confirmation of safety of this protocol.

In conclusion, a reduced dose schedule using PTV modification of IG-IMRT decreased the incidence of late GI toxicity without compromising PSA control. Therefore, careful target volume definition and fraction size are important for the safety of IG-IMRT.

\section{Conflicts of Interest}

The Authors state no conflicts of interest.

\section{References}

1 Zelefsky MJ, Chan H, Hunt M, Yamada Y, Shippy AM and Amols H: Long-term outcome of high dose intensity modulated radiation therapy for patients with clinically localized prostate cancer. J Urol 176: 1415-1419, 2006.

2 Alicikus ZA, Yamada Y, Zhang Z, Pei X, Hunt M, Kollmeier M, Cox B and Zelefsky MJ: Ten year outcomes of high dose, intensity modulated radiotherapy for localized prostate cancer. Cancer 117: 1429-1437, 2011.

3 Shu HG, Lee TT, Vigneault E, Xia P, Pickett B, Phillips TL and Roach M: Toxicity following high-dose three-dimensional conformal and intensity-modulated radiation therapy for clinically localized prostate cancer. Urology 57: 102-107, 2001.

4 Zelefsky MJ, Levin EJ, Hunt M, Yamada Y, Shippy AM, Jackson A and Amols HI: Incidence of late rectal and urinary toxicities after three-dimensional conformal radiotherapy and intensity modulated radiotherapy for localized prostate cancer. Int $\mathbf{J}$ Radiat Oncol Biol Phys 70: 1124-1129, 2008.

5 Odrazka K, Dolezel M, Vanasek J, Vaculikova M, Zouhar M, Sefrova J, Paluska P, Vosmik M, Kohlova T, Kolarova I, Navratil P, Brodak M, Prosvic P and Hoffmann P: Late toxicity after conformal and intensity-modulated radiation therapy for prostate cancer: Impact of previous surgery for benign prostatic hyperplasia. Int J Urol 17: 784-790, 2010.

6 Chen YJ, Suh S, Nelson RA, Liu A, Pezner RD and Wong JY: Setup Variations in Radiotherapy of Anal Cancer: Advantages of Target Volume Reduction Using Image-Guided Radiation Treatment. Int J Radiat Oncol Biol Phys 84: 289-295, 2012.

7 Zelefsky MJ, Kollmeier M, Cox B, Fidaleo A, Sperling D, Pei X, Carver B, Coleman J, Lovelock M and Hunt M: Improved Clinical outcomes with High-Dose Image Guided Radiotherapy Compared with Non-IGRT for the Treatment of Clinically Localized Prostate Cancer. Int J Radiat Oncol Biol Phys 84: 125129, 2012.

8 Guckenberger M, Ok S, Polat B, Sweeney RA and Flentje M: Toxicity after intensity modulated, image-guided radiotherapy for prostate cancer. Strahlenther Onkol 186: 535-543, 2010.

9 Nishimura T, Yamazaki H, Aibe N, Nakamura S, Yoshida K and Okabe H: Exceptionally high incidence of grade 2-3 late rectal toxicity in patients with prostate cancer receiving hypofractionated (2.2 Gy) soft tissue-matched image-guided intensity-modulated radiotherapy. Anticancer Res 33: 5507-5510, 2013.

10 Iwama K, Yamazaki H, Nishimura T, Oota Y, Aibe N, Nakamura $\mathrm{S}$, Ikeno $\mathrm{H}$, Yoshida $\mathrm{K}$ and Okabe $\mathrm{H}$ : Frequency and predisposing factors for interfractional rectal displacement requiring repeated precaution in prostate cancer patients treated with image-guided intensity-modulated radiation therapy. Anticancer Res 34: 7373-7378, 2014.

11 Iwama K, Yamazaki H, Nishimura T, Oota Y, Aibe H, Nakamura $\mathrm{S}$, Ikeno $\mathrm{H}$, Yoshida $\mathrm{K}$ and Okabe $\mathrm{H}$ : Analysis of intrafractional organ motion for patients with prostate cancer using soft tissue matching image-guided intensity-modulated radiation therapy by helical tomotherapy. Anticancer Res 33: 5675-5679, 2013.

12 R-project home page: https://www.r-project.org/

13 Yamazaki H, Nakamura S, Nishimura T, Yoshida K, Yoshioka Y, Koizumi $\mathrm{M}$ and Ogawa $\mathrm{K}$ : Transitioning from conventional radiotherapy to intensity-modulated radiotherapy for localized prostate cancer: changing focus from rectal bleeding to detailed quality of life analysis. J Radiat Res 55: 1033-1047, 2014. 
14 Vora SA, Wong WW, Schild SE, Ezzell GA, Andrews PE, Ferrigni RG and Swanson SK: Outcome and toxicity for patients treated with intensity modulated radiation therapy for localized prostate cancer. J Urol 190: 521-526, 2013.

15 Eade TN, Guo L, Forde E, Vaux K, Vass J, Hunt P and Kneebone A: Image-guided dose-escalated intensity-modulated radiation therapy for prostate cancer: treating to doses beyond 78 Gy. BJU Int 109: 1655-1660, 2012.

16 Dearnaley D, Syndikus I, Sumo G, Bidmead M, Bloomfield D, Clark C, Gao A, Hassan S, Horwich A, Huddart R, Khoo V, Kirkbride P, Mayles H, Mayles P, Naismith O, Parker C, Patterson H, Russell M, Scrase C, South C, Staffurth J and Hall $\mathrm{E}$ : Conventional versus hypofractionated high-dose intensitymodulated radiotherapy for prostate cancer: preliminary safety results from the CHHiP randomised controlled trial. Lancet Oncol 13: 43-54, 2012.

17 Yamazaki H, Nakamura S, Suzuki G, Yoshida K, Yoshioka Y, Koizumi M and Ogawa K: Hypofractionated Radiotherapy for Localized Prostate Cancer: A Challenging Accelerated Hypofractionated Radiotherapy. Anticancer Res 35: 5167-5177, 2015.

18 Lieng H, Pintilie M, Bayley A, erlin A, Bristow R, Chung P, Gospodarowicz M, Huang R, Ménard C, Warde P and Catton C: Long-term outcomes of a phase II trial of moderate hypofractionated image-guided intensity modulated radiotherapy (IG-IMRT) for localized prostate cancer. Radiother Oncol 122: 93-98, 2017

19 Michalski JM, Gay H, Jackson A, Tucker SL and Deasy JO: Radiation dose-volume effects in radiation-induced rectal injury. Int J Radiat Oncol Biol Phys 76: S123-129, 2010.

20 Pederson AW, Fricano J, Correa D, Pelizzari CA and Liauw SL: Late toxicity after intensity-modulated radiation therapy for localized prostate cancer: an exploration of dose-volume histogram parameters to limit genitourinary and gastrointestinal toxicity. Int J Radiat Oncol Biol Phys 82: 235-241, 2012.
21 Fellin G, Fiorino C, Rancati T, Pelizzari CA and Liauw SL: Clinical and dosimetric predictors of late rectal toxicity after conformal radiation for localized prostate cancer: results of a large multicenter observational study. Radiother Oncol 93: 197202, 2009.

22 Fiorino C, Fellin G, Rancati T, Vavassori V, Bianchi C, Borca VC, Girelli G, Mapelli M, Menegotti L, Nava S and Valdagni R: Clinical and dosimetric predictors of late rectal syndrome after 3DCRT for localized prostate cancer: preliminary results of a multicenter prospective study. Int J Radiat Oncol Biol Phys 70: 1130-1137, 2008.

23 Wust P, Joswig M, Graf R, Böhmer D, Beck M, Barelkowski T, Budach V and Ghadjar P: Dosimetric implications of inter- and intrafractional prostate positioning errors during tomotherapy: Comparison of gold marker-based registrations with native MVCT. Strahlenther Onkol, 2017. doi: 10.1007/s00066-0171141-x. [Epub ahead of print]

24 Expert Panel on Radiation Oncology-Prostate:, Zaorsky NG, Showalter TN, Ezzell GA, Nguyen PL, Assimos DG, D'Amico AV, Gottschalk AR, Gustafson GS, Keole SR, Liauw SL, Lloyd S, McLaughlin PW, Movsas B, Prestidge BR, Taira AV, Vapiwala $\mathrm{N}$ and Davis BJ: ACR Appropriateness Criteria( $\left.{ }^{\circledR}\right)$ external beam radiation therapy treatment planning for clinically localized prostate cancer, part I of II. Adv Radiat Oncol 2: 6284, 2016.
Received October 6, 2017

Revised October 19, 2017

Accepted October 20, 2017 